\title{
"A Kiss is But a Kiss": Cultural Mores, Ethical Relativism, and Sexual Harassment Liability
}

\author{
Frank J. Cavico*, Bahaudin G. Mujtaba*, Maria Petrescu and Stephen C. Muffler
}

The H. Wayne Huizenga School of Business and Entrepreneurship, Nova Southeastern University, Ft. Lauderdale, Florida, 33314, USA

\begin{abstract}
Sexual harassment legal liability has been one of the momentous legal outcomes of the 1964 Civil Rights Act. This seminal civil rights law in Title VII governing employment expressly prohibits discrimination based on sex (that is, gender). Two areas the courts have defined as sexual harassment have been quid pro quo (meaning "this for that") and hostile working environment. Quid pro quo claims take the form of "broken promises", "favors", or "threats" promised by male superiors to female subordinates in exchange for sexual favors or relationships. Hostile environment means any hostile, offensive, or intimidating action or environmental factor that would lead to the inability of the employee to work in a non-threatening atmosphere. This article examines the second type of sexual harassment cases - hostile environment. This article specifically focuses on certain physical aspects of perceived sexual harassment conduct, such as kissing, hugging, and touching, which in some cultures can be deemed as culturally and ethically appropriate but nonetheless can be perceived as hostile, offensive, abusive, intimidating, and threatening under the law. The authors present examples of socially acceptable behaviors around the world, analyze the legal ramifications, ethical implications, and cultural nuances, and then provide appropriate recommendations for business managers.
\end{abstract}

Keywords: Abusive, cultural nuances, hostile environment, hugging, intimidating, kissing, liability, offensive, Quid pro quo, Sexual harassment, touching.

\section{INTRODUCTION TO CULTURAL MORES}

As will clearly be seen in this article, the very nature of the definition of any illegal sexual behavior engenders a broad interpretation of what sexual harassment really is. Accordingly, such behavior is subjected to legal scrutiny and litigation. From a trial lawyer's perspective, this represents an excellent opportunity to find ways to hold companies accountable for their employees' purported sexual harassment behavior. The already complicated area of sexual harassment law is made even more complex when certain conduct of a sexual nature takes place in a multi-national and multicultural environment. This potentially litigious situation is exacerbated when there is a clash of cultural mores, norms, and practices against a vaguely defined law, perceived aggrieved parties, and perhaps opportunistic attorneys. Defining illegal and immoral sexual harassment clearly is much more difficult in a multi-national and multi-cultural environment. Under these circumstances, this study focuses on how cultural differences affect social interactions in the business world, from greetings to the perception of personal space, touching, and non-verbal communications, and how these differing cultural practices can engender lawsuits.

The global workplace today, whether in the U.S. or abroad, is now composed of employees from many different societies and cultures, bringing with them their divergent

*Address correspondence to these authors at the H. Wayne Huizenga School of Business and Entrepreneurship, Nova Southeastern University Ft. Lauderdale, Florida, 33314, USA; Tel: 954 262-5045;

E-mails: cavico@nova.edu; mujtaba@nova.edu societal values, moral norms, and cultural standards and practices [1]. All these heterogeneous employees will naturally be compelled to interact in the global, and increasingly "team" oriented, workplace. As will be seen, a practice that is considered morally and culturally appropriate in one culture may be perceived as demeaning and immoral by people in another culture. Also, the practice, perhaps of a sexual nature, though culturally based, may be deemed illegal pursuant to the sexual harassment law of the U.S. and other countries.

As to cultural practices, first, the authors examine the presumably innocuous practice of greeting someone. Greetings are influenced by cultural and personal characteristics and might change over time. For example, business people from Latin America are more likely to move from shaking hands to hugs and kisses as the business relationship progresses, while in countries such as the United Kingdom or Japan, the relationship is more likely to stick to more formal greetings [2]. These behavioral norms were not important or widely influential decades ago, because gender did not represent an issue in the business world due to the "glass ceiling", as well as the fact that international business and the multicultural workforce were not as widely developed as today.

However, in today's global economy, even if one just examines businesses in the United States, one still can perceive significant differences in the way greeting, touching, and "personal space" are viewed. This circumstance is due to changing demographics; and consequently the workforce in the U.S. has become highly multicultural as well as genderand age-diverse. Moreover, global diversity is a "fact of life" 
for business due to the development of international trade and business relations. The U.S. workforce is increasingly more ethnically and culturally diverse, with even just a few years ago approximately 85 percent of the new entrants into the workforce being women, minorities, and immigrants [3]. From this point of view, the employees and foreign business partners bring into the business relationship not only their skills and knowledge, but also their values, customs, and moral standards engrained in their cultures. Ethical relativism theories have shown that individual norms, values, and morals differ as a function of their cultures [4]. Behaviors that are considered acceptable and moral in some cultures might be totally offensive in other cultures; and this situation, as well be seen, represents a significant problem for businesses, especially in the context of sexual harassment.

An example of a problematic cultural practice concerns the Hispanic community and its cultural values. It is a common practice for some Hispanics to be very "open" about touching each other, including members of the opposite sex, as these people have a tendency to hug and kiss people whom they know and like. In the Hispanic community, as in many other parts of the world, "flirtation" is simply a way of socialization. The clothing that women wear may be considered provocative in other cultures, but is considered flattering to a woman's figure in the Hispanic culture. At times, it is also standard custom for men to compliment and politely stare at women they consider beautiful [5]. These practices are very popular and acceptable in the Hispanic culture. Consequently, because Hispanics now are the largest minority group in the U.S.- - surpassing African-Americans in 2005-what can happen when fellow employees, employers, lawyers, the Equal Employment Opportunity Commission, and the courts begin to receive many complaints against Hispanics for these types of acceptable behaviors [5]?

To demonstrate the cultural clash further, in the Arab world, the greatest sign of trust is to "share one's air". This is a practice wherein Arab men literally touch noses with their business associates in an intimate gesture of trust, where air from one's breath is shared with the other individual. In the U.S., where one's "space" is considered a protected area, such a practice could effectively foster a noticeable hostile and offensive environment [5].

Furthermore, in some parts of the Asian and African business community, women are not considered equals. Therefore, when women managers attempt to deal with men, they are shunned "at best" and belittled "at worst". U.S. companies promote (or should do so) based on business results, but local custom may foster a countervailing discriminatory and intimidating environment, not based on the company itself, but rather on external cultural forces, which may be beyond the scope of the individual company practically but for which it may be legally responsible [5].

Greeting behavior presents its own unique set of challenges. An example that shows how cultural differences can bring inferences in communication is related to the American soldiers who served in Iraq. While Iraqis are likely to be welcoming and open to communication, the relation with American soldiers is not established easily, especially because the U.S. way of doing business is "getting straight to business", instead of allowing an initial period for greeting and social conversation. Another major difference is the fact that men routinely shield their wives and daughters from contact with outsiders, which can also represent a major issue for foreign companies doing business in the region without the necessary knowledge regarding cultural and social norms [6].

Even if cultures are relatively similar, there might be significant differences between the utilized and accepted forms of business greetings. Most Europeans shake hands each time they meet and leave, while Americans shake hands less often than Europeans. Both cultures shake hands much more often and more firmly than most Asian cultures [7]. For example, a bow, or "Namaste", is much more common and appreciated in the Indian culture than a handshake when dealing with women [7].

Even from the point of view of verbal communication in the greeting process, Americans are less formal than other cultures when saying "hi", addressing based on first names, and shaking hands freely, even between genders. Other cultures can be much more formal and have different greeting ceremonials.

The Chinese culture, a major "player" in the international trade market, emphasizes formal rules, such as respect for senior persons and hierarchy, even when greeting other persons. Another difference that needs to be considered is the fact that the order of names is reversed, and as a result most Chinese individuals identify themselves by using the last name first. In Japan, as in other Asian cultures, a common greeting gesture is represented by the bow [8]. What complicates this practice is the fact that it has many subtle nuances as to who bows first, how low, and how long [8]. The bow can be used at the beginning, during, and at the end of the interaction, and it is usually not expected from foreign individuals. The exchange of business cards is also important in this culture [8].

Zimbroff [9], moreover, points to two studies conducted in Asia which shed some light on cultural mores and sexual harassment. One was a 2002 study of Asian college students, consisting of mainland Chinese, Korean, Japanese, and people from Hong Kong, that were compared to non-Asian students who were primarily of Canadian descent. According to Zimbroff [9], "the respondents were asked to provide their reactions to given scenarios on the Sexual Harassment Attitude Scale (SHAS) with the goal of measuring perception of harassment in variety of situations. On a number of items, Asian students were significantly more tolerant of actions deemed to constitute sexual harassment than were non-Asian respondents. Interestingly, in those cases where respondents of Asian descent moved or lived in Canada, as the length of residency in Canada increased, the less tolerant they were of sexual harassment". The second study Zimbroff [9] points to is a 2005 Singaporean study of sexual harassment responses by four major ethnic groups-Chinese, Malays, Indians, and Caucasians, who were students and staff members at four universities that responded to a variety of verbal and nonverbal cues as to sexual harassment. The study indicated that "the perception of sexual harassment often resulted from a breakdown of communication and a distortion of cues (by either perpetrator or victim of both) that was attributed to socially-derived values.... Malays, strongly influenced by 
Islamic teachings, were significantly more likely to rate a touch on the shoulder as harassing than any of the other groups. Caucasians were the only group to rate a touch on the shoulder as less harassing than a comment about someone looking sexy. The researchers stressed the importance of investigating cross-cultural perceptions of sexual harassment in order to improve cultural sensitivity in the diverse, international communities in which more and more citizens of the world will be employed" [9].

Middle Eastern cultures also have distinct greeting norms compared to Western or Asian countries' norms. Handshakes are very common among men, as well as hugs and kisses on both cheeks; and the custom of exchanging business cards is also important [7]. Nevertheless, there are strict norms regarding greeting women and their interaction with male counterparts. In this context, the much less formal American style can easily lead to gestures and behavior perceived as offensive and even as sexual harassment by different cultures. While cheek kissing is accepted in the Middle East between friends and family, it is usually reserved for men. Handshakes or kisses between men and females in social or business circumstances are usually not accepted or recommended [7]. Of special importance is the greeting process in the habit of cheek kissing which presents variations even among Western cultures.

Cheek kissing thus is another type of conduct that can cause problems. To illustrate, with a rich historical and cultural background, European greeting norms include cheek kissing, with wide variations from one country to another. For example, British customs include the cheek kiss just once, on the right cheek, usually reserved for family and friends; whereas the Belgians, the Dutch, and the Swiss use the three times norm, usually left-right-left [7]. Very little kissing is done in Germany in business circumstances; and consequently it is rather a controversial and not widely accepted custom. For example, a society in Germany that advises on etiquette and social behavior, the Knigge Society, has even called for kissing to be banned in the workplace, because the practice of greeting colleagues and business partners with a kiss on the cheek is uncomfortable for many Germans, since it is not representative of, or acceptable by, the German culture [10]. The Society's recommendations, therefore, are to stick to formal handshakes in the business environment [10].

The French customs differ from one region to another, from one kiss to three. Moreover, it is also common for many French regions to kiss both cheeks twice. A popular saying states that one can guess in what French region he is located just by the kiss customs [7]. The Mediterranean and Latin cultures include more informal business behavior norms; and thus the social kiss is an accepted form of salutation, especially between women and men or between women [8]. Due to a European and Latin influence, the kiss on the cheek in workplace and business circumstances is becoming more common even in the United States. Some of the reasons include not only immigration, but also the increased number of women in the workplace [11]. However, this fact can represent a serious issue of sexual harassment when dealing with a multicultural workforce and with unclear business behavior norms.
Touching and non-verbal communication are also problematic types of conduct. Research studies have shown that at least $75 \%$ of all communication is non-verbal, with significantly higher rates for high-context cultures that use even more gesturing and non-verbal cues [12]. Under these circumstances, eye contact is an important non-verbal communication tool, which conduct also presents variations from one culture to another. While in Western cultures, it is recommended to maintain eye contact with the conversation partner, especially in business negotiations or in job interviews, to confirm interest and engagement; but in other cultures, such as China, eye contact can be perceived as rude and disrespectful [8].

Touching other people and personal space are also important gestures and behaviors in all cultures, thereby producing norms that vary widely from one culture to another. For example, in the Middle East men should not touch women in public, not even in a social context such as public transportation [12]. In the same cultures, only the right hand is used for touching, since it is assumed that the left hand is used for hygiene and bodily functions [8]. In Western cultures, touching and hugging are usually initiated by the person higher in rank or with more seniority, who usually initiates handshakes, hugging, or other forms of socially acceptable gestures, such as a touch on the head, a pat on the back or on the shoulder [8].

Touching customs and norms are greatly complicated by religious meanings assigned to the standards of conduct. For example, many Asian people believe the head houses the soul, so when another person touches his or her head, it places one in jeopardy [8]. Nevertheless, touching is not a preferred form of greeting in most Asian countries; and consequently personal gestures, such as patting someone on the back, are not common in Japan. In other countries, embraces and hugs are routine, especially in South American countries. Habits in countries like Mexico and Costa Rica also commonly include physical contact, such as hugs as well as pats on the back or shoulder [8].

There are also important gender differences when it comes to using a touch as a form of communication. Morreale, Spitzberg, and Barge [13] note that women are more likely to hug and use a touch to express support and affiliation, while men use the touch to assert power. In recent decades, gender differences regarding social touching and business communication, especially in the workplace, have become an important source of many sexual-harassment cases [8]. From this point of view, a pat on the back or on the arm might easily go from being a collegial recognition or encouragement gesture to being perceived as sexual intimidation or condescending behavior, especially if multiculturalism and multiple meanings are involved in the situation. The result could well be accusations of illegal and unethical conduct. Accordingly, the next section examines the ethical environment of such cultural practices, specifically pursuant to the theory of Ethical Relativism.

\section{CULTURAL MORES AND MORALITY - ETHICAL RELATIVISM ANALYSIS}

Ethical Relativism as an ethical theory also harkens back to ancient Greece and the philosophical school of the Soph- 
ists as well as the philosophical school of the Skeptics. Ethical relativists deny that there are any objective, universal moral rules from which one can construct an absolute moral system. Ethical relativists deny that there are moral rules applicable to all people, in all societies, and at all times. There are thus no universal moral standards by which to judge an action's morality; rather, morality is merely relative to, and holds for, only a particular society at a particular time. "When in Rome, do as the Romans", said the ethical relativists. Morality, therefore, is a societal-based notion; it is nothing more than the morality of a certain group, people, or society at a given time. What a society believes is right is in fact right for that society; the moral beliefs of a society determine what is "right" or "wrong" in that society. However, different societies may have different conceptions of what is right or wrong. What one believes is right, the other may believe as wrong. Consequently, the same act can be morally right for one society but morally wrong for another.

Pursuant to Ethical Relativism there are no moral standards which are universally true for all people, in all societies, and at all times; and since there is no way to demonstrate that one set of beliefs is true and the other false, the only way to determine an action's morality is to determine what the people in a particular society believe is right or wrong at a given time. Of course, ascertaining exactly what a society is emerges as a daunting challenge. Even within a homogeneous society, there are diverse cultures, subcultures, social classes, kinship, and work groups; and in a heterogeneous society there will be many smaller sub-societies that co-exist. All these components of society may reflect different standards, mores, customs, and beliefs, including moral standards and beliefs. Yet pursuant to the doctrine of Ethical Relativism, one must attempt to find the pertinent "society" and then try to ascertain that society's moral beliefs; but when one does ascertain the societal beliefs, standards, and practices regarding morality, one simply has to conform and adopt, and one will be acting morally, at least according to the ethical theory of Ethical Relativism [4].

Already a complex issue legally and practically, sexual harassment problems are made even more complicated in international business by ethical relativism [3]. Researchers have already shown that the issue of sexual harassment is influenced by differences in religion, political ideology, level of industrialization, beliefs about women, traditions and laws [3]. Whether employees view sexual conduct in the workplace as "right" or "wrong" or moral or immoral will be influenced by their respective cultural backgrounds and particularly their societal ethical norms. Consequently, it is very important to know one's environment and to ascertain the pertinent "society" and its cultural and moral norms. As such, it is very important to know the characteristics of the culture and the social setting where the interaction takes place. If business transactions, negotiations, and work take place in a foreign country, it is important to be well informed regarding the local customs of greeting and social interactions, especially if there is a moral component to such conduct. In a multicultural setting, such as the international workplace, it thus is always a very good idea to know the cultural background of employees and to establish a working environment that is adapted to these specifics, in order to prevent any potential moral as well as legal issues related to sexual harassment. The next section of the article examines the legal environment of cultural practices of a perceived sexual nature.

\section{CULTURAL MORES AND LEGALITY - LEGAL ANALYSIS}

Practices in the workplace of a perceived sexual nature, such as kissing, as well as other form of physical social interaction, involve the possible legal liability for these actions. To complicate matters, some of these practices may be culturally based. Zimbroff [9] underscores the relationship of culture and law, to wit: "All individuals strongly internalize their cultures of origin. Employees from different cultures, even those who have lived in a country like the United States for some period of time, may define what constitutes a hostile environment (in relation to sexual harassment) different from their peers". Therefore, in the American workplace, one must be keenly aware of legal liability pursuant to U.S. civil rights laws regarding sexual harassment for culturally based practices. One must also be aware of the extra-territorial effect of U.S. civil rights law, as well as the fact that many other countries also have laws prohibiting sexual harassment.

\section{A. Sexual Harassment Law in the U.S.}

Pursuant to Title VII of the Civil Rights Act of 1964, as interpreted by the U.S. Supreme Court in the seminal Meritor Savings Bank v. Vinson [14] decision, sexual harassment is a form of sex discrimination which is illegal under U.S. law [14-19]. Initially, however, it is important to note that the law does not proscribe all conduct of a sexual nature in the workplace; consequently only unwelcome sexual conduct will constitute a legal violation [14-19].

Sexual harassment can encompass unwelcome sexual advances, requests for sexual favors, as well as other verbal and physical harassment of a sexual nature [14-19]. This conduct must explicitly or implicitly adversely affect a person's employment, unreasonably interfere with a person's work performance, or create an intimidating, hostile, or offensive work environment [14-19]. However, the law in the U.S. does not prohibit simple teasing, offhand comments, or isolated instances which are not very serious in nature; yet harassment is illegal when it is so frequent, pervasive, and severe that it creates the aforementioned hostile environment [14-19]. Moreover, the EEOC when investigating complaints of sexual harassment will examine the whole record and the totality of the circumstances, including the circumstances of the alleged harassment, the nature of the sexual conduct, and the context in which the alleged incidents occurred. A determination of the legality of a particular action is made based on the facts of the case on a case-by-case basis [1420].

Determining Whether a Workplace Environment is "Hostile". The Supreme Court ruled in the Meritor Savings Bank case that to violate Title VII of the Civil Rights Act the sexual harassment must be "sufficiently severe or pervasive" so as to alter working conditions and create an "abusive working environment" [14]. There are several factors to determine if a workplace environment is abusive, intimidating, hostile, or offensive, to wit: "(1) whether the conduct was verbal or physical, or both; (2) how frequently it was re- 
peated; (3) whether the conduct was hostile and patently offensive; (4) whether the alleged harasser was a co-worker or a supervisor; (5) whether the others joined in perpetuating the harassment; and (6) whether the harassment was directed at more than one individual" [15-19]. The key legal standard for determining if the alleged harassment is sufficiently severe or pervasive is the objective standard of the "reasonable person" [15-19]. As such, according to one federal district court, the law is not to be used "as a vehicle for vindicating the petty slights suffered by the hypersensitive" [15-19, 21]. Consequently, "if the challenged conduct would not substantially affect the work environment of a reasonable person no violation should be found" [14-19]. The EEOC provides an illustration, to wit: "Sexual flirtation or innuendo, even vulgar language that is trivial or merely annoying, would probably not establish a hostile environment" [14-19].

The EEOC, however, has brought considerable confusion to the so-called objective standard by bringing in a subjective element. That is, the EEOC further states that "the reasonable person standard should consider the victim's perspective and not stereotyped notions of acceptable behavior [14-19]. The EEOC then provides an example, to wit: "A workplace in which sexual slurs, displays of 'girlie' pictures, and other offensive conduct abound can constitute a hostile work environment even if many people deem it to be harmless and insignificant" [14-19]. In order to establish this subjectivity standard, the complaining party merely has to testify that he or she found the alleged conduct to be hostile, offensive, or abusive when it occurred [22]. Moreover, unless the alleged perpetrator can produce evidence to the contrary, for example, the conduct of the complaining party, "the subjective prong of the analysis will be satisfied" [22]. Consequently, what the EEOC has "accomplished" is to completely conflate objective and subjective standards in determining a "hostile" workplace, thereby substantially complicating the life of employers, managers, employees, attorneys, and judges and juries.

Moreover, to further exacerbate the confusion as well as enlarge the legal pitfalls for employers, the courts are not uniform in applying legal standards that should apply in sexual harassment cases. Lewis [23], in examining the case law, finds that the courts have used three different standards, to wit: 1) a "reasonable woman" standard; 2) a "reasonable person" standard; and 3) a "reasonable victim" standard. The "reasonable woman" standard means the courts will focus on the unique female's perception of harassing conduct; the "reasonable person" standard focuses on the impact of the harassing conduct on a reasonable person; and the "reasonable victim" standard focuses on the perception of the aggrieved party [23]. The courts that use the latter standard and abjure the "reasonable person" standard do so because the "reasonable person" standard might "reinforce the prevailing level of discrimination" and result in the harassers continuing "to harass merely because a particular discriminatory practice was common" [23]. Druhan [24] explains the rationale behind the "reasonable woman" standard, to wit: "The court applied the reasonable woman standard because women have different experiences with harassment and different perceptions about what constitutes harassment". The "reasonable woman" standard also allows for "flexibility" and "respects the differences" between female and male views on sexual harassment [24].

Regarding this key issue in the law, the conclusion, posits Lewis [23], is that it is a "difficult to task to determine" the standards the courts will apply. In addition, the Second Circuit U.S. Court of Appeals has stated that since the line between merely boorish behavior and illegal sexual harassment is not a precise one, judges should allow juries to resolve such issues at trial rather than judges deciding them beforehand [25]. Having juries resolve these issues means, obviously, that the employer is now engaged in defending itself in a federal lawsuit involving a perhaps sympathetic jury.

Welcome v. Unwelcome Conduct. Critical to the analysis herein is the distinction the law makes between "welcome" and "unwelcome" sexual conduct. The Supreme Court emphasized in the Meritor decision that to be legally actionable the sexual actions or conduct must be "unwelcome" [14]. Ramsini [26] explains the rationale for the "unwelcome" requirement, to wit: It makes at least intuitive sense why the Supreme Court would characterize unwelcomeness as the 'gravamen' of any sexual harassment claim. After all, courts are not in the business of awarding damages to plaintiffs who were confronted with conduct that they, in fact, welcomed". Accordingly, as part of the complaining party's initial hostile environment case she or he must prove that the conduct was "unwelcome". "Unwelcome conduct" means that the complaining employee did not solicit or incite the conduct and that the complaining employee regarded the conduct as undesirable or offensive [15-18]. However, there is a major problem with this "unwelcome" requirement; and that is the Supreme Court has not decided from what perspective the "unwelcomeness" analysis should take place. Ramsini [26] points out that "the Supreme Court has not explicitly told lower courts from which perspective the analysis should take place". Consequently, Ramsini [26] describes the "multiple perspectives" the lower federal courts have used to determine whether conduct was unwelcome, to wit: "The court could ask whether the plaintiff subjectively perceived the accused's conduct as unwelcome, or whether a reasonable person in her position would perceive the conduct as unwelcome, or whether a reasonable person in his position would have known that the plaintiff did not welcome his conduct. Due to the lack of direction from the Supreme Court, the courts of appeals have developed their own tests, most of which do not involve a clear perspective".

Regardless of the perspective, from an evidentiary standpoint an important fact is whether the aggrieved communicated that the conduct was unwelcome. As such, the EEOC emphasizes:

When there is an indication of unwelcomeness or when the credibility of the parties is at issue, the charging party's claim will be considerably strengthened if she made a contemporaneous complaint or protest. Particularly when the alleged harasser may have some reason (e.g., prior consensual relationship) to believe that the advances will be welcome, it is important for the victim to communicate that the conduct is unwelcome [18].

Moreover, evidence of the complaining party's conduct, dress, or speech, particularly if deemed "provocative", is admissible on the issue of whether the sexual conduct was 
unwelcome [14]. However, the courts and the EEOC are cognizant of the fact that sexual attraction and actions often may play a role in daily social interactions among employees and that people do at times use sexually explicit language as well as tell off-color jokes [18]. Finally, if an employee has willingly participated in conduct of a sexual nature, but then ceases to do so and claims that any continuing conduct has created a hostile work environment, the burden, says the EEOC, is on the employee to demonstrate that the further sexual conduct is unwelcome and rises to the level of workrelated harassment [18].

Isolated Instances of Harassment. Another problematic area of the law pertinent to the examination herein is the liability for isolated instances of harassment. As a general rule, a single incident or isolated incidents of offensive sexual conduct or remarks will not create a hostile or abusive environment; rather, there usually must be some type of a pattern of offensive conduct [18]. However, a single incident of harassment may be sufficient to constitute a legal violation if it is severe; and the more severe the harassment is, the less need to show a repetitive series of incidents [18]. In reviewing recent case law, Concannon [27] concludes that "taken together, the...cases stand for the proposition that a significant showing of severity can overcome a relative lack of frequency (or 'pervasiveness') of such conduct. This is so even if the conduct in question consists only of verbal harassment". One court tried to explain the level of physical harassment required to sustain a sexual harassment claim. In Hostetler v. Quality of Dining, Inc. [28], the court stated: "There are some forms of physical contact which, although unwelcome and uncomfortable for the person touched, are relatively minor. Even more intimate or more crude physical acts - a hand on the thigh, a kiss on the lips, a pinch on the buttocks - may be considered sufficiently abusive to be described as 'severe' when they occur in isolation.... When the harassment moves beyond the sort of casual contact which (if it were consensual) might be expected between friendly co-workers, and manifests in more intimate, intrusive forms of contact, it becomes increasingly difficult to write the conduct off as a pedestrian annoyance".

The EEOC, moreover, presumes that any unwelcome, intentional touching of a person's intimate body areas is sufficiently severe to be offensive and alter working conditions and thus constitute a legal violation [18]. In such a case, the burden is on the alleged aggressor (and employer) to demonstrate that the unwelcome touching conduct was not sufficiently severe to create a hostile work environment.

Employer Vicarious Liability for Unlawful Sexual Harassment. Assuming there is unlawful sexual harassment, another significant aspect of the law deals with the employer's vicarious liability for sexual harassment by its managers and supervisors. Vicarious liability means that the liability of an employee is imputed to the employer; there is no need of evidence that the employer itself acted in any wrongful manner [29]. In the momentous Supreme Court cases of Burlington Industries $v$ Ellerth [30] and Faragher v. City of Boca Raton [31] the Court enunciated a principle of absolute liability in sexual harassment law [19]. Absolute liability principles are very rare in the law. One old and still valid example would be liability for extra-hazardous activities, such as building dams, spaying pesticides, and blasting for construction [29]. Nonetheless, there is now one in sexual harassment law and practice. The Supreme Court in the aforementioned cases held that when a manager or supervisor sexually harasses a subordinate employee who suffers a tangible employment action, such as a job loss, or adverse job action the employer is absolutely liable; there is no defense (presuming there is no "Machiavellian" scheme to defraud the employer). According to the EEOC, a "supervisor" is a person who "has the authority to recommend tangible employment decisions affecting the employee or if the individual has the authority to direct the employee's daily work activities" [15]. Such a definition would apply to the typical manager too. Furthermore, the EEOC defines a "tangible employment action" as "a significant change in employment status", encompassing "hiring, firing, promotion, demotion, undesirable reassignment, a decision causing a significant change in benefits, compensation, decisions, and work assignments" [15].

The Supreme Court, however, also enunciated a principle of conditional liability. If there is sexual harassment but no adverse employment action the employer does have an affirmative defense, to wit: (1) the employer must demonstrate that it used reasonable care to prevent or promptly correct any harassment; and (2) the employee failed to act in a reasonable manner by not taking advantage of any preventive or corrective opportunities supplied by the employer or to otherwise avoid the harm [15-17, 30, 31].

U.S. Culture and Sexual Harassment Case Law. The pertinent U.S. case law indicates that ethical and/or cultural relativism, however, as an affirmative defense in a US workplace sexual harassment claim, may present problems in the U.S. judicial system for the employee and employer. In the United States courts, as emphasized, the "unwelcomeness" element found in the legal definition of sexual harassment is generally based on the victim's reaction to the act in question [32]. This fact weakens most defenses that the harasser was only acting para-sexual in a cultural sense since in the workplace the coworker victim's reaction to such conduct is the key to determining "unwelcomeness". Further, the Ninth Circuit Court of Appeals has held that whether or not the conduct is sufficiently severe or pervasive is to be determined under the "reasonable victim" standard [32]. The Ellison [32] court explained how the standard is to be interpreted by stating that:

In evaluating the severity and pervasiveness of sexual harassment, we should focus on the perspective of the victim". In so doing, the court should discount "stereotyped notions of acceptable behavior" and keep in mind that "what many men may not consider objectionable may offend many women". The reasonable victim standard . . . classifies conduct as unlawful sexual harassment even when harassers do not realize that their conduct creates a hostile working environment". Therefore, the alleged harasser's intent is unimportant and "compliments" are not a defense (pp. 879-880).

The legal logic weakening an ethical or "cultural" based permissible conduct defense to workplace sexual harassment claims was also indirectly addressed in Richardson v. New York State Dep't of Correctional Serv. [33]. In Richardson [33], the court rejected the narrow approach of a "reasonable person of the plaintiff's group" and opted to continue to fol- 
low the "reasonable person" standard in discrimination cases under Title VII. The Richardson [33] court refused to go down the preverbal "rabbit-hole" by explaining:

In adopting this standard as the proper one under Title VII, we reject the view of those courts that look to the perspective of the particular ethnic or gender group, e.g., a "reasonable African-American" or a "reasonable Jew"....we believe that examining hostile environment claims from the perspective of a "reasonable person who is the target of racially or ethnically oriented remarks" is the proper approach. First, Title VII seeks to protect those that are the targets of such conduct, and it is their perspective, not that of bystanders or the speaker, that is pertinent. Second, this standard makes clear that triers of fact are not to determine whether some ethnic or gender groups are more thin-skinned than others. Such an inquiry would at best concern largely indeterminate and fluid matters varying according to location, time, and current events. It might also lead to evidence, argument, and deliberations regarding supposed group characteristics and to undesirable, even ugly, jury and courtroom scenes [33, p. 436, FN 3].

Sexual harassment claims are based on Title VII. Consequently, the Richardson [33] court's rationale and warning applies to any harasser's legal defense in a U.S. courtroom that the actor's "cultural" or "ethnic" background could justify, otherwise unacceptable, "offensive" sexual conduct in the workplace.

Workplace diversity and cultural sensitivity without rational "guardrails" erected to curtail common-place parasexual physical greetings in the workplace, for example, as noted, common in Latin American cultures, can lead to negative consequences. As such, employees who acquiescence to a customary kiss on the cheek in the Latino culture would logically not be precluded to file a sexual harassment claim when that kiss becomes far more aggressive. To illustrate, see the federal appeals court case of Perez-Cordero v. WalMart Puerto Rico, Inc. [34], in which the employer's summary judgment was vacated and reversed, when the court reviewed the facts alleged in the employee's sexual harassment complaint. The First Circuit Court of Appeals in PerezCordero [33] held that the employee's participation and "acquiescence to the customary greeting" among employees at a Puerto Rican Wal-Mart of a kiss on the cheek was not "in any way probative of his receptiveness" to an incident in which the harasser "forcefully sucked on his neck" [34]. The more aggressive kiss was well outside the customary display of content neutral para-sexual displays of affection deeply engrained in certain cultures. The aforementioned Wal-Mart case justifies absolute company policies that forbid such physical contact between employees as a way to avoid the "slippery slope" argument of which physical touching or greetings are acceptable when avoiding sexual harassment claims.

In the U.S., there is also a state law case that relates to sexual conduct and culture. The Nebraska Supreme Court dealt with an underlying factual pattern where a female professor at Creighton University had sent alleged sexually harassing e-mails to another female professor. In Roxana Recio v. Michelle Evers [35], Recio sued Evers for intentional interference with a business relationship after Ever's internal grievance successfully alleged that Recio had sexually harassed her and which placed her on probation and requiring her to attend mandatory counseling. Both professors worked in the Spanish department and the subject e-mails were exchanged in Spanish, between individuals with Latin American heritage over the course of a few months. Recio took the position that her e-mails were taken out of context and generally their true innocent meanings were lost in translation. At a five day internal disciplinary hearing conducted by the University complaint committee, one fellow professor explained in Recio's defense that her e-mails could be "explained away by culture and effusiveness" [35]. However, the University's internal grievance board believed that the emails, even when accounting for cultural differences, were inappropriate. The court highlighted the grievance board's decision by stating:

The committee found that Recio's messages were inappropriate, noting that "[w]itnesses from various Hispanic cultures including Cuba, Venezuela, Spain, and Puerto Rico differed with ... Recio's interpretation that culture could be used to explain away" the e-mails and had described them as "inappropriate, shocking, and of a sexual nature". The committee found that "[at] best, the emails in their intensity and obsessiveness are ominous and caused ... Evers great distress" [35, p. 129].

Ultimately, the Nebraska Supreme Court upheld summary judgment in favor of Evers since Evers' internal complaint was not maliciously filed and was truthful, which amounted to an affirmative defense to Recio's tortious interference claim [35, p. 137]. The case law indicates, therefore, that employers, business managers, as well as employees must realize that standards of what might be acceptable in society at large - culturally as well as ethically - do not always correspond to what is legally acceptable in the workplace.

\section{B. Extra-territoriality of U.S. Law}

U.S business managers not only have to be aware of the impact of U.S. civil rights law in the United States, but also must be cognizant of the fact that U.S. civil rights laws have extra-territorial effect of U.S. law. The Civil Rights Act of 1991 mandates that U.S. Civil Rights laws have extraterritorial effect. This important employment discrimination issue concerns the rights of workers employed by a U.S. employer or by a foreign employer in a foreign country workplace. The difficult issue is whether the extensive U.S. legal protections afforded to employees in the U.S. carry overseas. This legal question typically is regarded as an issue of the "extraterritoriality" of U.S. law. The leading employment discrimination extraterritoriality case was the Supreme Court's 1991 decision in EEOC v. Arabian American Oil Company. In the so-termed Aramco case, the Supreme Court was called upon to decide whether Congress intended to apply Title VII of the Civil Rights Act of 1964 to United States citizens working for U.S. companies in foreign countries. The Supreme Court ruled that Title VII did not reflect the requisite clear expression of U.S. Congressional intent to overcome the presumption against extraterritoriality of statutes. Consequently, the Court held that the protections of Title VII did not extend to a U.S. citizen working for a U.S. company overseas [29]. 
However, very soon after the Supreme Court had ruled in the Aramco case, Congress attempted to overrule the decision by at least partially extending U.S. employment discrimination law overseas. Accordingly, the Civil Rights Act of 1991 was promulgated to protect certain employees of U.S. firms overseas. Congress thereby expressly amended and enlarged the scope of Title VII to provide a clear indication of Congress's extraterritorial intent to reach U.S. business firms that operate outside the U.S. as well as those under the "control" of a U.S. entity. The 1991 amendments to the Civil Rights Act expanded the definition of the key term "employee" to include any U.S. citizen employed by a U.S. company in a foreign country or by a foreign company that is controlled by a U.S. firm. Foreign employees working within the U.S. are protected, whether working for U.S. or foreign multinational firms, as are U.S. citizen employees. However, and most significantly, outside the U.S., only U.S. citizens working for U.S. firms or firms controlled by U.S. firms are protected because foreign employees were expressly excluded from protection when employed in a foreign country, even by a U.S. firm. Therefore, the Civil Rights Act of 1991 amended Title VII to extend certain extraterritorial protections against discrimination, including sexual harassment, to many employees [29]. The U.S. business manager, moreover, not only has to be aware of the extra-territorial effect of U.S. law, but also must be cognizant of the fact that many countries today have civil rights and non-discrimination law, including prohibitions against sexual harassment in the workplace. Although it is beyond the scope of this article to supply an exhaustive legal comparison of sexual harassment laws, the authors in the next section do wish to provide certain perspectives of sexual harassment law in the global environment and make some succinct comparisons to U.S. law.

\section{Global Legal Perspectives}

In the United Kingdom, the key statute is the Protection from Harassment Act of 1997, which makes all forms of harassment a civil wrong as well as a criminal offence. The Act prohibits conduct which amounts to harassment of another person. Harassment is defined in terms of the effect on the person being harassed; and the term includes alarming the person or causing him or her distress. This Act allows for damages to be collected or an injunction to be issued prohibiting the harassment. The Remedies for Harassment component of the Harassment Act 1997 creates both criminal and civil actions against a person who pursues a course of harassing conduct $[36,37]$. The Protection from Harassment Act was primarily enacted to deal with the problem of "stalking", but in fact the law covers numerous types of public order and personal disputes and work situations, including bullying and harassment at work. Harassment includes any unwanted conduct that has the effect of violating dignity or creating an intimidating, hostile, degrading, humiliating, or offensive environment. Harassment can take many forms and occur for a variety of reasons. It may be related to age, sex, race, color, national origin, disability, religion, sexuality, or personal characteristics of any individual. Sexual harassment is defined as unwanted conduct of any sexual nature affecting the dignity of women and men in the workplace, which can include unwelcome physical, verbal and even non-verbal conducts [36]. Sexual harassment, as such, refers to persis- tent unwanted sexual advances, typically in the workplace, where the consequences of refusing are potentially very disadvantaging to the victim [1].

Another important statute in the United Kingdom is the Employment Equality Act of 1998, which construes harassment as any act or conduct encompassing spoken words, gestures, or the production, display or circulation of written words, pictures or other materials, if the action or conduct is unwelcome to the recipient and could reasonably be regarded, in relation to the relevant characteristic of the recipient, as offensive, humiliating, or intimidating. Typical harassing behavior encompasses the following actions: (1) verbal Harassment in the form of jokes, comments, ridicule, songs, inappropriate comments, suggestions, and namecalling; (2) written harassment, Including faxes, text messages, emails, and notices; (3) physical harassment, such as jostling, shoving, or any form of harmful or offensive touching; (4) intimidator harassment in the form of inappropriate looks, gestures, posturing, or threatening poses, as well as interference with or damage to property, threats, or extortion; (5) visual displays, such as posters, emblems, flags, and badges; (6) isolation or expulsion from work or social activities; and (7) pressure to behave in a manner that a person thinks is inappropriate, for example, being required to dress in a manner unsuited to a person's ethnic or religious background [37].

The Employment Equality Act of 1998, in addition, views sexual harassment as any act of physical intimacy or request for sexual favors. The statute also includes other acts or conduct, including spoken words, gesture, or the production, display, or circulation of written words, pictures, or other material, which is unwelcome and could reasonably be regarded as sexually offensive, humiliating, or intimidating. The following are examples of behavior that could reasonably be regard as sexually offensive, humiliating, or intimidating: (1) physical conduct of a sexual nature, such as un-wanted physical conduct, for example, unnecessary touching, hugging, patting, pinching, or brushing against another's body, hair, or clothing, as well as, of course, any type of sexual assault, battery, and coercive sexual intercourse; (2) verbal conduct of a sexual nature, including unwelcome request for sexual favors, unwelcome sexual advances, propositions or pressure for sexual activities, continued suggestions for dates or social activity outside the workplace, particularly after it has been made clear that such suggestions are unwelcome, unwanted or offensive flirtations, offensive jokes, suggestive remarks, sexual innuendos (double-meaning comments of a sexual nature), lewd comments, inquiring about a person's sexual preferences, fantasies, or activities; (3) non-verbal conduct of a sexual nature, including the display of pornographic or sexual suggestive pictures, objects, computer pornography, written materials, emails, text messages or faxes, and also including leering, whistling, and sexually suggestive gestures, movements, or facial expressions; (4) sex-based conduct, including conduct that denigrates or ridicules, or is intimidating, or is physically abusive of a person because of his or her sex, such as derogatory or degrading remarks or insults about his or her gender or body [36].

Japan, in 1991, enacted an antidiscrimination law that requires employers to prevent sexual harassment. However, 
sexual harassment in Japan was not treated with the same degree of seriousness and priority as in the United States. For example, few Japanese companies had training programs specifically designed to prevent sexual harassment, whereas most U.S. employers, especially large ones, do. Furthermore, there is still a "clash of cultures when it comes to business practices in Japan versus the U.S., as shown by the stillcommon Japanese executive practice of asking lower-level female employees to serve tea to guests [29, 38]. Consequently, in 1997, Japan amended its Equal Employment Opportunity Law to specifically regulate sexual harassment. Accordingly, the Japanese Civil Code now provides a basis of judicial relief in both contract and tort form for the two main types of sexual harassment: quid pro quo and hostile working environment [38]. Regarding the hostile environment form of sexual harassment, the Civil Code provides that any person who intentionally or negligently infringes on another person's rights is subject to tort liability. The word "rights" has been defined as encompassing not only statutory rights, but also legally protected interests that are considered in need of protection. Again, if the "hostile" type of sexual harassment amounts to a recognized tort-such as assault or battery, invasion of privacy, or defamation-there will be no problem in asserting that the conduct infringes on a legally protected interest and thus constitutes a tort. However, if the alleged abusive or offensive sexual conduct does not constitute a recognized tort, the critical liability question will have to be judicially resolved as to whether a legally protected interest is at stake and, if so, which one. Regarding the employer's liability for sexual harassment under Japanese law, the employer is held to a legal duty to make sure the workplace is conducive to working and that employees are treated with dignity and can do their jobs. If a manager fails to meet this legal duty, the employer will be vicariously liable for the manager's failure [38].

In Peru, the Law of Labor Competitiveness and Productivity was the first Peruvian legislative norm to address sexual harassment generally. Due to an ongoing desire to attract foreign investment, the law applies to all private-sector enterprises and treats foreign and Peruvian companies alike, meaning that there is no preferential treatment for "local" companies. Thus, foreign subsidiaries are treated as local employers and their employees are covered by this law. The prohibited sexual harassment encompasses not only physical acts against the employee but also verbal acts against the employee or the employee's family, acts of discrimination based on sex, immoral acts, and acts adversely affecting the employee's dignity [39].

In India, the Supreme Court ruled that sexual harassment in the workplace violated the fundamental rights granted in the Indian Constitution to gender equality and the rights to life, liberty, and equal treatment. Article 15 of the Constitution specifically prohibits discrimination on the basis of sex as well as religion, race, caste, and place of birth. Also, Article 19 states that all Indian citizens are entitled to practice any profession [40]. Sexual harassment in India, like in the U.S., is broadly defined. The Indian Supreme Court construes sexual harassment as unwelcome sexual behavior that a harassment victim reasonably perceives may negatively impact one's health and safety in the workplace [40]. Moreover, in one aspect, Indian sexual harassment law is even broader than in U.S. law. Feld [40] points out that while in the U.S. sexual harassment needs to be "severe or pervasive", in India, "the definition of sexual harassment does not explicitly require that the harassing behavior occur over time. Instead, the guideline language implies that an incident, or only a few incidents, can constitute harassment.....The Court...thereby indicat(es) that harassing incidents do not have to be persistent to constitute a valid sexual harassment claim. Moreover, the Court declares that sexual harassment includes any single act that outrages the modesty of a woman". Furthermore, in order to combat sexual harassment in the Indian workplace, employers must create a complaint procedure, resolve sexual harassment claims, institute disciplinary actions, and, where necessary, effectuate prosecution of sexual harassment offenders [40]. It is very interesting to point out that the sexual harassment complaint committee must be headed by a woman and must be at least half-comprised of women. The employer also must notify its employees of the sexual harassment policy. Article 32 of the Constitution grants the Court the power to enact guidelines providing remedies to those who have suffered a violation of Constitutional rights, which the Court has done in the case of sexual discrimination and harassment [40].

French law prohibits sexual harassment; and the law has both criminal and civil consequences. This article will briefly address the civil law aspects pertaining to employment. The Labor Code of 2012 states that no employee shall be required to submit to sexual harassment; and defines sexual harassment as "the fact of imposing on a person, in a repeated manner, words or behavior with a sexual connotation, which undermine his or her dignity by reason of their humiliating or degrading nature or create against him or her an intimidating, hostile or offensive situation" [41]. The law also imposes an obligation on employers to "take all necessary actions with a view of preventing acts of sexual harassment" [41]. The emphasis on harming one's "dignity", according to Hebert (2013, p. 14), "introduce(s) a new conception of sexual harassment into the provisions of the Labor and Penal Codes", which were originally promulgated in 1992. Hebert [41] also points out that the 2012 law was "inspired by Anglo-Saxon notions of harassment"; yet Hebert also relates that this fact is a "source of irony" in that "legislators and others in France have also expressed concern that French sexual harassment law not reflect the perceived 'excesses' of the United States' sexual harassment law'. Sexual harassment, therefore, must be understood not only in crosscultural and ethically relativistic perspectives, but also "cross-legal" perspectives [42]. Taking all these perspectives into consideration, the authors in the next section of the article discuss the implications for employers, managers, and employees, and then make appropriate recommendations.

\section{IMPLICATIONS AND RECOMMENDATIONS}

The advent of the global economy, manifested by increasingly diverse and multi-national and multi-cultural workplaces, means that employers must be cognizant of sexual harassment law in the context of the cultural experiences and backgrounds their employees bring to the workplace. Accordingly, the authors raise the following implications from this potentially perilous "intersection" of law and cul- 
ture, as well as provide certain practical recommendations to employers, managers, and employees.

First and foremost, know the law. The laws of a country as well as the office policies and rules of a business can shed light on the best practices regarding greeting and social interactions in a business setting. For example, in the United States, regulations and good practices regarding sexual harassment have developed significantly during the last years and can be a source of guidance for business interactions. Other countries also offer a rich body of information regarding their customs and social norms, which can be applied not only in that foreign environment, but also with employees coming from that culture. For example, Middle Eastern cultures and other countries that practice the religious (sharia) law are a good source of information regarding the norms of behavior in a business environment [37]. Overall, performing research and collecting information, avoiding ethnocentrism, and paying attention to interlocutors' preferences and habits can improve business and work relationships and prevent many legal problems.

A principal implication to be drawn from the analysis herein is that when one combines diverse cultural mores and ethical relativism-based moral norms with a broad definition of sexual harassment in the U.S., including myriad and imprecise legal standards, encompassing objective and subjective components, as well as a principle of absolute employer liability, one consequently confronts a legal, ethical, and practical quandary. The dilemma is further exacerbated by the fact that U.S. law has extraterritorial effects as well as the fact that many countries now have similarly broad definitions of and prohibitions against sexual harassment. One risk of these broad definitions is that a "flood of frivolous Title VII cases" will ensue [43]. In essence, what is still missing from the courts' decisions and EEOC legal guidelines surrounding sexual harassment is the key issue of how the U.S. legal system, premised on the old English common law system, is to deal with cultural and ethical differences that arise from those people, especially employees, who do not hold traditional Anglo-Saxon values, ethical norms, and cultural mores.

Employers, business managers, human resource professionals, and attorneys naturally are looking for guidance from the courts and the EEOC as to the standards to be applied to sexual harassment cases as well as how one should balance the dictates of the law with cultural mores and practices. So what are the employer, manager, and employee to do to resolve this cultural, ethical, and legal clash? What is the proper standard to be used to determine sexual harassment? And where is the line between illegal abusive, hostile, intimidating, and offensive conduct and merely legal vulgar, boorish, uncivil, uncomfortable, annoying, and mildly offensive conduct? The legal system will consider all the circumstances on a case-by-case basis regarding allegations of sexual harassment based on a hostile, abusive, or offensive work environment. Yet how will the courts weigh the offensiveness, the severity, the pervasiveness of the conduct with its context, which can include a legitimate cultural component? Directly "on point" is Supreme Court Justice Antonin Scalia's warning that the courts must draw a distinction between discriminatory employment conduct and "ordinary socializing in the workplace" [44], and especially so if the latter has a cultural component.

There are thus many dilemmas and challenges in this area of the law where legal principles can clash with cultural norms. Accordingly, the authors provide some specific and presumably helpful advice. Regarding the employee, it must be emphasized that the EEOC strongly recommends that a party aggrieved by sexual harassment inform the harasser directly that the conduct is unwelcome and must cease; moreover, the aggrieved party should use any employer complaint mechanism or grievance system available [17]. The EEOC further states that "victims are well-advised to assert their right to a workplace free from sexual harassment. This may stop the harassment before it becomes more serious. A contemporaneous complaint or protest may also provide persuasive evidence that the sexual harassment in fact occurred as alleged. Thus, in investigating sexual harassment charges, it is important to develop detailed evidence of the circumstances and nature of any such complaints or protests, whether to the alleged harasser, higher management, coworkers, or others" [18]. All employees, principally through their employers' efforts, must become educated and sensitized as to the meaning of sexual harassment, especially in a multi-national and multi-cultural workplace. However, as Zimbroff [9] counsels: "While employees would not be expected to become cultural psychologists, employees would be expected to anticipate the potential for the perception of gender-based disrespect, humiliation, or offensiveness by others, even in comments or actions that would seem harmless or tolerable to them or individuals of their own culture".

Regarding employers, the EEOC emphasizes that prevention is the best way to eliminate sexual harassment in the workplace. Accordingly, employers should take certain necessary steps to ensure that sexual harassment does not occur, for example, clearly and strongly communicating to employees that sexual harassment is wrong and will not be tolerated, providing sexual harassment training, developing methods to sensitize employees as to sexual harassment, establishing effective complaint and grievance procedures, taking immediate appropriate action when the employee complains about sexual harassment, and developing appropriate sanctions from reprimand to discharge [Code of Federal Regulations, Section 1604.11, 2011; 15-18]. Furthermore, the EEOC advises that the employer's policy and procedure should encourage the victims of sexual harassment to come forward, should not require the victim to complain first to any offending supervisor, should require confidentiality as much as possible, and should protect victims and witnesses from retaliation as much as possible [16].

Based on the preceding legal, ethical, cultural, and practical analysis as well as the aforementioned EEOC recommendations, the authors further suggest the following:

- The employer should develop policies and procedures, especially in the form of training programs and seminars, to make all concerned culturally aware and competent and to sensitize them as to conduct which could be construed as intimidating, hostile, or offensive. Zimbroff [9] emphasizes that "as business becomes more diverse and international, educational programs for managers and employees at all levels will have to incorporate cultural relativism". 
- Employers should meet with various stakeholders (company owners, management, employees and union representatives) and discuss and develop a reasonable e-mail and computer monitoring system in the workplace. This conversation should first start with education explaining how such technology has resulted in increased sexual harassment claims by employees. Many of these communications can be "lost in translation" even if culturally and/or ethically acceptable in the computer user's mindset. Further, once a policy is adopted, it should be circulated throughout the company with mandatory clickon log-in warnings to all users that they are aware of the policy and that their computer usage will be monitored and that they consent to such monitoring. This notice is critical as it will effectively dispel any reasonable expectation of privacy claims by the computer users.

- The employer must inculcate the value of diversity - not only for its own inherent value, but also as an instrumental value-creating practice in the modern global economy. However, the employer also must be aware that respecting diversity and being sensitive to the employees; cultural beliefs and practices may be "good multiculturalism" [9, p. 1334] and "good" ethics, but "bad" legally pursuant to the broad and subjective legal definitions of sexual harassment.

- The employer should create an ombudsman type position; and the ombudsman should have the authority to monitor compliance with the policies, to solicit, receive, and investigate complaints about perceived sexual harassment and retaliation, and to maintain records of all sexual harassment and retaliation complaints.

- The employer should establish "ethics hotlines" or "whistleblowing hotlines" (phone, text, email) for the employees to report (anonymously initially) sexual harassment and retaliation complaints.

- The employer should purchase sexual harassment insurance as the employer may become liable based on the Supreme Court's absolute liability principle even if it was not in any way culpable or negligent.

- Know your partners. Greeting and behavior in a business environment are related not only to cultural background, but also to priorities given, for example, to persons in senior positions or the elderly. From this point of view, individuals should try to know their discussion partners in advance and then find the necessary information regarding their cultural background, position in the company, seniority, and other relevant facts. The more one is able to adapt to one's partners' customs, the more likely one will be to gain their trust, appreciation, and thus avoid any misunderstandings, which could degenerate into accusations of immorality and/or illegality.

- Copying may not be bad. When in doubt, wait it out, or, better yet, try to see what others do. That is, ascertain how people do the introductions and the greeting procedures and acts based on this introductory behavior. The same strategy especially applies when dealing with a diverse workforce. In such a case, letting an employee in control of the social interaction dictate the norm might provide the necessary information regarding the custom- ary and proper actions to be followed. Accordingly, let the other person take the lead; and then observe what the preferred interaction model appears to be. If a person wants to start with a handshake, follow his or her lead, and thus do not "go for" a kiss or a hug. If a person reaches for a kiss or for a hug, reciprocate in a professional manner. Taking into consideration others' preferences is a very good way to avoid legal and ethical sexual harassment issues.

- Less might be more. That is, do not engage in more social interaction and touching than the social setting, legal precepts, and cultural norms allow. For example, in "tricky" situations, a smile or a nod might be the option to choose. A handshake is also a generally accepted greeting in the business world and at the workplace. However, even these can get individuals into trouble if they do not have enough information regarding gender differences and local norms, particularly of a religious nature. Accordingly, one recommendation would be to let the women initiate social contacts in business meetings that involve Asian and Middle Eastern cultures.

- "A kiss is but a kiss". When the business setting allows a social kiss, let the other person initiate it, and make sure to remember that the general customs are for one kiss in the U.S. and two in Europe. Yet, to avoid any potential issues with sexual harassment or accusations of immoral conduct, make sure one does not "go for" a kiss unless one is introduced to a person in a social situation or one knows the person from the workplace, and the person initiates the kiss. Wet kisses, sounds, smacking, and lingering are clearly not acceptable, while hand placement needs to be carefully strategized so no doubts, awkwardness, and discomfort can appear.

The authors trust that by recognizing the implications of this potential cultural legal and ethical class, as well as by adhering to their recommendations, businesses, employers, and managers will be able to avoid adverse legal, ethical, and practical consequences in the multinational and multicultural workplace.

\section{SUMMARY}

In today's competitive global economy, U.S. companies must be ready to "go global" and thus attempt to commence business ventures wherever business opportunities exist. Companies also must hire the "best" employees available, which means companies will recruit globally and likely end up with a diverse workforce. In either case there may arise a clash between cultural mores and the law. Does this mean the U.S. courts will attempt to hold U.S. firms accountable for sexual harassment conduct due to cultural pattern and practices from other countries, or international firms doing business in the U.S., as well as U.S. firms doing business extraterritorially? The answer to all these questions very well could be "yes"! The issue of sexual harassment and the cultural differences and the resulting legal, ethical, and practical challenges inherent in a cultural and legal conflict should be of paramount importance to employers, managers, human resource professionals, and attorneys. Moreover, it will be most interesting to see how this conflict will be resolved, because the courts still have not comprehensively addressed 
this situation. This topic may become the new, fertile ground that produces the next "big wave" of sexual harassment claims and lawsuits, particularly because sexual harassment law is plainly not clear very vague, and replete with subjectivity. To avoid sexual harassment lawsuits and to establish and maintain a legal, ethical, and efficacious workplace, the authors have provided some suitable recommendations. Most importantly, though, the authors, to conclude, strongly urge all employers to develop, inculcate, and sustain a workplace environment solidly based on the values of diversity, cultural competency, sensitivity, civility, dignity, and respect.

\section{ABOUT AUTHORS}

Frank J. Cavico is a Professor of Business Law and Ethics at the H. Wayne Huizenga School of Business and Entrepreneurship of Nova Southeastern University in Ft. Lauderdale, Florida. He has been involved in an array of teaching responsibilities, at the undergraduate, master's and doctoral levels, encompassing such subject matter areas as business law, government regulation of business, constitutional law, administrative law and ethics, labor law and labor relations, healthcare law, and business ethics. In 2000, he was awarded the Excellence in Teaching Award by the Huizenga School; and in 2007 and 2012, he was awarded the Faculty Member of the Year Award by the Huizenga School of Business and Entrepreneurship; and in 2014 he was named Professor of the Year by the Huizenga School. He holds a J.D. from the St. Mary's University School of Law and an LL.M from the University of San Diego, School of Law; and is a member of the Florida and Texas Bar Associations. He is the author and co-author of several books and numerous law review and management journal articles.

Bahaudin G. Mujtaba is Professor of Management and Human Resources at the H. Wayne Huizenga School of Business and Entrepreneurship of Nova Southeastern University in Ft. Lauderdale, Florida. Bahaudin is the author and coauthor of several professional and academic books dealing with diversity, ethics, and business management, as well as numerous academic journal articles. During the past twentyfive years he has had the pleasure of working with human resource professionals in the United States, Brazil, Bahamas, Afghanistan, Pakistan, St. Lucia, Grenada, Malaysia, Japan, Vietnam, China, India, Thailand, and Jamaica. This diverse exposure has provided him many insights in ethics, culture, and management from the perspectives of different firms, people groups, and countries.

Maria Petrescu is an Assistant Professor of Marketing at Nova Southeastern University. Maria has a Ph.D. in Business Administration and Marketing from Florida Atlantic University and a M.B.A. from Nova Southeastern University. She participated and published in prestigious conferences and publications, such as the American Marketing Association Summer Educators' Conference, the AMS World Marketing Congress, the Academy of Marketing Science Conference, the Journal of Product and Brand Management and the Journal of Internet Commerce. In 2014 she also published a book on Viral marketing and social networks.

Stephen C. Muffler is a full-time attorney and member of the Florida Bar since 1993 and an adjunct professor of
Business Law and Ethics at the H. Wayne Huizenga School of Business and Entrepreneurship of Nova Southeastern University in Ft. Lauderdale, Florida since 1999. He was awarded the Adjunct Professor of the Year at H. Wayne Huizenga School of Business and Entrepreneurship of Nova Southeastern University in 2007; and has taught graduate business law and ethics classes in five countries. He was a former legal assistant to the Florida Bar's ethics enforcement branch in Miami Florida and former Special Public Defender for the $17^{\text {th }}$ Judicial Circuit, in and for Broward County Florida. He currently is Special Counsel to the Broward County Sheriff's Department, the largest accredited public safety agency in the state of Florida. His civic service has included being the Chairman of the City of Fort Lauderdale's Citizen Police Review Board and the Executive Director of the City of Key West's Citizen Review Board, both of which investigate and/or review administrative complaints against municipal police officers. He has authored and co-authored various articles on legal \& ethical topics, and occasionally lectures by invitation to national and local organizations on various law and professionalism issues. He holds a J.D. from Nova Southeastern University and an LL.M from the University of Miami, School of Law.

\section{CONFLICT OF INTEREST}

The authors confirm that this article content has no conflict of interest.

\section{ACKNOWLEDGEMENTS}

Declared none.

\section{REFERENCES}

[1] Mujtaba BG. Workforce diversity management: Challenges, competencies and strategies. $2^{\text {nd }}$ ed. Florida: ILEAD Academy 2010.

[2] Samovar LA, Porter RE, McDaniel ER. Communication between cultures. $7^{\text {th }}$ ed. Boston: Wadsworth, Cengage Learning 2009.

[3] Gee MV, Norton SM. The confluence of gender and culture: sexual harassment in the international arena. Manag Decis 1999: 37(5): 417-23.

[4] Cavico FJ, Mujtaba BG. Business ethics: the moral foundation for effective leadership, management, and entrepreneurship. $3^{\text {rd }}$ ed. Boston, Massachusetts: Pearson Publishing Company 2013.

[5] Cates SV. Sexual harassment and cultural conflict. In Cavico, Frank J, Mujtaba, Bahaudin G, Eds. Legal Challenges for the Global Manager and Entrepreneur. Dubuque, Iowa: Kendall Hunt Publishing Company 2008; pp. 515-8.

[6] Tierney J. Baffled occupiers, or the missed understandings. New York Times 2013. Retrieved from: http://www.nytimes.com/ 2003/10/22/international/middleeast/22LETT.html

[7] Gesteland RR. Cross-cultural business behavior. marketing, negotiating, sourcing and managing across cultures. Copenhagen: Copenhagen Business School Press 2002.

[8] Samovar LA, Porter RE, McDaniel ER. Communication between cultures. $7^{\text {th }}$ ed. Boston: Wadsworth Cengage 2009.

[9] Zimbroff J. Cultural differences in perceptions of and responses to sexual harassment. Duke J Gender L Policy 2007; 14: 1311-41.

[10] BBC. German etiquette group targets workplace kissing 2011. Retrieved from: http://www.bbc.co.uk/news/mobile/world-europe14487415

[11] Olson E. Better not miss the buss. New York Times 2006. Retrieved from http://www.nytimes.com/2006/04/06/fashion/ thursdaystyles/06kiss.html?pagewanted=all\&_r=0

[12] Trompenaars F, Hampden TC. Riding the waves of culture. understanding cultural diversity in business. London: Nicholas Brealey Publishing 1998. 
[13] Morreale SP. Spitzberg BH. Barge K. Communication: motivation, knowledge, skills. $3^{\text {rd }}$ ed. New York: Peter Lang International Academic Publishers 2007.

[14] Meritor Savings Bank v. Vinson 1986. 477 U.S. 57, 69, 1986, 106 S. Ct. 2399.

[15] Equal employment opportunity commission 2014. Facts About Sexual Harassment. Available from: http://www1.eeoc.gov/eeoc/ publications/fs-sex.cfm

[16] Equal employment opportunity commission 2014. Sexual harassment. [Retrieved August 28, 2014] Available from: http://www1.eeoc.gov//laws/types/sexual_harassment.cfm

[17] Equal employment opportunity commission 2014. Questions and answers for small employers on employer liability for harassment by supervisors. [Retrieved august 28, 2014] Available from: http://www1.eeoc.gov/policy/docs/harassment-facts.html

[18] Equal employment opportunity commission 1990. Policy guidance on current issues in sexual harassment, number N-915-050, 3/19/90. [Retrieved August 28, 2014] Available from: http://www1 1.eeoc.gov/policy/docs/currentissues.html

[19] Equal employment opportunity commission 1999. Enforcement guidance on vicarious employer liability for unlawful harassment by supervisors. Number 915.002, 6/18/99. [Retrieved August 28, 2014] Available from: http://www1.eeoc.gov/policy/docs/ harassment.html

[20] Code of Federal Regulations 2011. Title 29, Labor, Part 1604, Guidelines on discrimination because of sex, Section 1604.11, Sexual Harassment. [Retrieved August 28, 2014] Available from: http://www.gpo.gov/fdsys/pkg/CFR-2011-title29-vol4/xml/CFR2011-title29-vol4-part1604

[21] Zabkowicz v. West Bend Company, 589 F. Supp. 780, 784. Eastern District of Wisconsin 1984.

[22] Equal employment opportunity commission 1994. Enforcement Guidance on Harris v. Forklift Sys., Inc., No. 92-1168, Number 915.002. [Retrieved August 28, 2014] Available from: http://www1.eeoc.gov/policy/docs/harris.html

[23] Lewis MM. Sexual harassment in the workplace: hurdles of a modern "Rosie the Riverter". Duquesne Bus Law J 2013; 15: 199-223.

[24] Druhan VB. Severe or pervasive: an analysis of who, what, and where matters when determining sexual harassment. Vanderbilt Law Rev 2013; 66: 355-96.

[25] Schiano v. Quality payroll systems, 445 F. $3^{\text {rd }}$ 597. Second Circuit Court of Appeals 2006.

[26] Ramsini LK. The unwelcome requirement in sexual harassment: choosing a perspective and incorporating the effect of supervisorsubordinate relations. Wm Mary Law Rev 2014; 55: 1961-2001.
[27] Concannon J. Actionable acts: "severe" conduct in hostile work environment sexual harassment cases. Buffalo J Gender L Soc Policy 2011-2012; 20: 1-21.

[28] Hostetler V. Quality of dining, Inc., 218 F.3d $798\left(7^{\text {th }}\right.$ Circuit 2000).

[29] Cavico FJ, Mujtaba BG. Legal challenges for the global manager and entrepreneur. $2^{\text {nd }}$ ed. Dubuque, Iowa: Kendall Hunt Publishing Company 2014.

[30] Burlington Industries, Inc. v. Ellerth 1998. 118 S. Ct. 2257.

[31] Faragher v. City of Boca Raton 1998. 118 S. Ct. 2275.

[32] Ellison v. Brady, 924 F.2d 872, 879. $9^{\text {th }}$ Cir. 1991.

[33] Richardson v. New York State Dep't of Correctional Serv., 180 F.3d 426, 436. Second Circuit Court of Appeals 2000.

[34] Perez-Cordero v. Wal-Mart Puerto Rico, Inc., 656 F.3d 19. First Circuit Court of Appeals 2011

[35] Roxana RV, Michelle E. 771 N.W.2d 121. Nebraska Supreme Court 2009.

[36] Gilani SRS, Cavico FJ, Mujtaba, BG. Harassment in the workplace: a practical review of the laws in the United Kingdom and the United States. Public Org Rev 2014; 14: 11-8.

[37] Gilani SRS, Khan AW, Mujtaba BG. Islam, shari'a laws and international human rights compatibility for expatriate business managers. J Bus Stud Q 2014; 6(2): 98-109.

[38] Yamakawa R. "We've only just begun: the law of sexual harassment in Japan. Hastings Int Comp L J 1999; 22: 523-58.

[39] Orihuela S, Montjoy A. The evolution of latin America's sexual harassment law: a look at mini-skirts and multinationals in Peru. Calif West Int L J 2000; 30: 323-44.

[40] Feld L. Along the spectrum of women's rights advocacy: a crosscultural comparison in the United States and India. Fordham Int *1 L J 2002; 25: 1205-81

[41] Hebert CL. Divorcing sexual harassment from sex: lessons from the French. Duke J Gender L Policy 2013; 21: 1-37.

[42] Petruscu M. Kiss and tell. Nova Southeastern University, Huizenga School of Business, Faculty Blog August 25, 2014. [Retrieved August 29, 2014] Available from: http://huizenga.nova.edu/facultyblog

[43] Vohs K. "I don't know the question, but sex is definitely the answer": the over-simplification of same-sex sexual harassment since Oncale V. Sundowner Offshore Services, Inc. Wm Mitchell L Rev 2014; 40: 1641-6.

[44] Oncale v. Sundowner offshore servs 1998. Inc., 523 U.S. 75.

Received: February 02, 2015

Revised: March 09, 2015

Accepted: March 11, 2015

() Cavico et al.; Licensee Bentham Open.

This is an open access article licensed under the terms of the Creative Commons Attribution Non-Commercial License (http://creativecommons.org/licenses/by-nc/3.0/) which permits unrestricted, non-commercial use, distribution and reproduction in any medium, provided the work is properly cited. 